\title{
Optimization of Metal Inert Gas Welding (MIG) Parameters using Design of Experiments (DoE): A Review
}

\author{
[B.F. Jogi*, N.S. Tupe, M.B. Todkar, R.S. Pawade and P.K. Brahmankar]
}

\begin{abstract}
Metal inert gas welding (MIG) is a fusion welding process having wide applications in various industries. In this process proper selection of input welding parameters is necessary in order to obtain a good quality weld and subsequently increase the productivity of the process. In order to obtain a good quality weld, it is necessary to control the input welding parameters. MIG welding parameters are the most important factors affecting the quality, productivity and cost of welding. This paper presents the influence of welding parameters like welding current, welding voltage, gas flow rate, wire feed rate, etc. on weld strength, weld pool geometry on the base material during welding. Design of Experiments (DoE) methods used to optimize the parameters for target quality. A plan of experiments based on Taguchi technique has been used to acquire the data. The objective functions have been chosen in relation to parameters of MIG welding bead geometry, tensile strength, bead width, bead height, penetration and heat affected zone (HAZ) for quality target. Optimal parameters contribution of the MIG operation was obtained via grey relational analysis (GRA). Furthermore, survey of the analysis of variance (ANOVA) is also performed to validate the optimized parameters.
\end{abstract}

Keywords-MIG welding, Optimization, DoE methods

\section{Introduction}

As per industry and research point of view, to control the process input parameters are important to obtain a desirable welded joint with the required weld quality for any joining process $[1,2]$. However, it requires a time consuming trial and error development method. In other words, there is often a more ideal welding input parameters combination, which can be used. In order to overcome this problem, various optimization methods can be useful to define the desired output variables through developing mathematical models to specify the relationship between the input parameters and output variables. Design of experiment (DoE) techniques [3] has been applied to carry out such optimization. Taguchi method has been also adapted for many applications in different areas. Furthermore, for optimization in the Taguchi's method the term signal represents the desirable

B.F. Jogi*, R.S. Pawade and P.K. Brahmankar Faculty, Department of Mechanical Engineering Dr. B.A. Technological University, Lonere-Raigad 402103 Maharashtra State, India

N.S. Tupe, M.B. Todkar

Students, Department of Mechanical Engineering

Dr. B.A. Technological University, Lonere-Raigad 402103

Maharashtra State, India value (mean) for the output characteristic and the term noise represents the undesirable value (standard deviation, SD) for the output characteristic. Therefore, signal to noise $(\mathrm{S} / \mathrm{N})$ ratio to the mean to the $\mathrm{SD}$. S/N ratio is used to measure the quality characteristic deviating from the desired value.

\section{Metal Inert Gas Welding (MIG)}

Metal inert gas welding (MIG) is one of the widely used techniques for joining ferrous and non ferrous metals. MIG welding offers several advantages like joining of dissimilar metals, low heat affected zone, no slag, no flux is used. MIG weld quality is strongly characterized by weld bead geometry $[1,2]$. Hence it is planned to do review on the metal inert gas welding (MIG) process parameters using DoE methods [3].

MIG may be operated by semiautomatic or automatic modes. Semiautomatic welding, where equipment controls only the electrode wire feeding. However, movement of welding gun is controlled by manually. This may be called hand-held welding. In the machine welding a gun is connected to a manipulator. An operator has to constantly set and adjust controls that move the manipulator. However, in automatic welding process the equipments welds without the constant adjusting of controls by a welder or operator. On some equipments, automatic sensing devices also control the correct gun alignment in a weld joint [4].

Figure 1 and 2 depict the working condition and principal of MIG welding process respectively. The electrode in this process is in the form of coil and if fed continuously towards the joint during the process. At the same time inert gas (e.g. argon, helium, suitable mixture of these or $\mathrm{CO}_{2}$ ) is passed around electrode from the same torch [2]. Inert gas is used to prevent the atmosphere from contacting the molten metal and HAZ. The arc may be produced between a continuously fed wire and the work piece. When gas is supplied, it gets ionized and an arc is initiated in between electrode and work piece. Electrode melts due to the heat and molten filler metal falls on the heated joint. Continuous welding with coiled wire helps high metal depositions rate and high welding speed. The filler wire is generally connected to the positive polarity of direct current (DC) source forming one of the electrodes. The work piece is connected to the negative polarity. The power source could be constant voltage, DC power source, with electrode positive which yields a stable arc and smooth metal transfer with least spatter for the entire current range. Some torch has water cooling systems. MIG welding is also called Gas Metal Arc Welding (GMAW).

MIG welding applications: All commercially important applicable metals such as carbon steel, high-strength, low- 
alloy steel, and stainless steel, aluminum, copper, titanium, and nickel alloys can be welded in all positions with this process by choosing the appropriate shielding gas, electrode, and welding variables $[1,2,4]$.

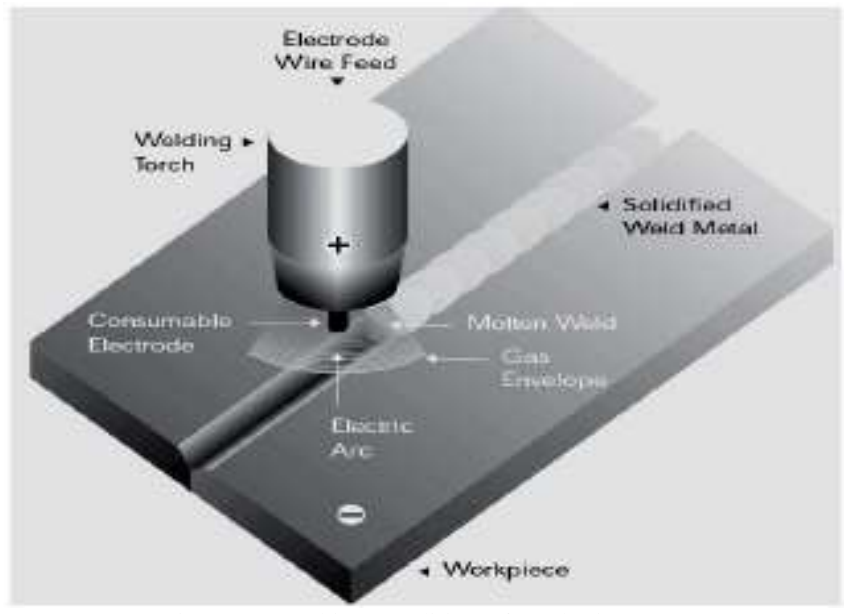

Figure 1. Working condition of work piece [1].

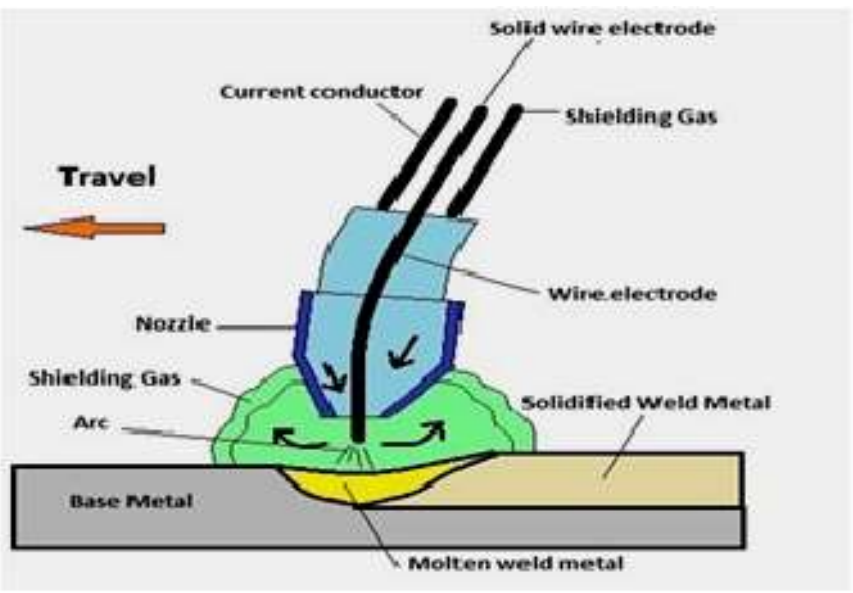

Figure 2. Working principles of GMAW [2, 5]

\section{MIG Process Parameters}

Weld quality and weld deposition rate are influenced by the various welding parameters and joint geometry. The weld bead geometry, depth of penetration and overall weld quality depends on the following operating variables:

- Electrode size, welding current, arc voltage

- Arc travel speed, welding position

- Gas flow rate, shielding gas composition

- Electrode extension (length of stick out) [5].

Electrode Size: The electrode diameter influences the weld bead configuration, the depth of penetration, bead width and has a consequent effect on the travel speed of welding process also. As a thumb rule, for the constant welding current (wire feed speed setting) the arc becomes more penetrating as the electrode diameter decreases. To get the maximum deposition rate at a constant current, the smallest diameter wire will provides the necessary penetration of the weld. The higher electrode diameters create weld with less penetration but wider in width. The electrode wire diameter depends on the thickness of the work piece, the required weld penetration, the desired weld profile and deposition rate, the position of welding and the cost of electrode wire. Commonly used electrode sizes are (mm): 0.8, 1.0, 1.2, 1.6 and 2.4. Each size has a usable current range depending on the wire composition and spray type arc or short circuiting arc is used [5].

Welding Current: The value of welding current used in MIG has the greatest effect on the deposition rate, the weld bead size, shape and penetration. In MIG welding, metals are generally welded with direct current polarity electrode positive (DCEP), as it provides the maximum heat input to the work and therefore a relatively deep penetration can be achieved. However, all the other welding parameters are held constant; increasing the current will increase the depth, the width of the weld penetration and the size of the weld bead also [5].

Welding voltage: This is a very important variable in MIG welding, mainly because it determines the type o metal transfer by influencing the rate of droplet transfer across the arc. When all the variables such as the electrode composition and sizes, the type of shielding gas and the welding technique are held constant, the arc length is directly related to the arc voltage. High and low voltages cause an unstable arc. Excessive voltage causes the formation of excessive spatter, porosity and overlapping at the edges of the weld bead; in the fillet welds it increases undercut and produces narrower beads with greater convexity. However, an excessive low voltage may cause porosity. The arc voltage to be used depends on base metal thickness, type of joint, electrode composition and size, shielding gas composition, welding position, type of weld and other factors [5].

Shielding Gas: The shielding gas and its flow rate have a substantial effect on the arc characteristics, mode of metal transfer, penetration and weld bead profile, speed of welding, cleaning of action and weld metal mechanical properties. Argon, helium and argon-helium mixtures are used in many applications for welding non-ferrous metals and alloys. Argon and carbon dioxide are used in carbon steel [5].

Arc Travel Speed: For a constant current, slower travel speeds proportionally provide larger bead and higher heat input to the base metal because of the longer heating time. If the travel speed is too slow, unusual weld build up occurs, which causes poor fusion, lower penetration, porosity, slag inclusions and a rough uneven bead [5].

\section{Design of Experiments}

Design of Experiments (DoE) is a powerful statistical technique introduced by R. A. Fisher in England in the 1920 's to study the effect of multiple variables simultaneously [3]. The DoE using Taguchi approach can economically satisfy the needs of problem solving and product/process design optimization projects. By learning and applying this technique, engineers, scientists, and researchers can significantly reduce the time required for experimental investigations. DoE is a technique of defining and investing all possible combinations in an experiment involving multiple factors and to identify the best combination. In this, different factors and their levels are identified. 
The advantages of design of experiments are as follows:

- Numbers of trials are significantly reduced

- Important decision variables which control and improve the performance of the product or the process can be identified

- Optimal setting of the parameters can be find out

- Qualitative estimation of parameters can be made

- Experimental error can be estimated

- Inference regarding the effect of parameters on the characteristics of the process can be made.

Thus, DoE is a method to identify the important factors in a process, identify and fix the problem, and identify the possibility of estimating interactions.

DoE techniques are full factorial, fractional factorial, Taguchi orthogonal array and Response surface method (Central Composite design). Furthermore, ANOVA stands for Analysis for Variance and it is the tool used for the analysis of contribution of each process parameter on response parameter. Mathematical models are used to establish the relationship between the input and output parameters in welding processes. "MINITAB" and "Design Expert" are the software used for DoE techniques and ANOVA [3].

\section{v. Optimization of MIG}

Jha et al. [6] studied the corrosion resistant properties by source of depositing laying of stainless steel on low carbon steel components with an ability of gaining maximum economy and enhanced life. Study carried out on single beads of stainless steel using solid filler wire of diameter 1.2 $\mathrm{mm}$ on $8 \mathrm{~mm}$ thick low carbon steel. To understand the perfect results in experimentation, a statistical software Design expert 9.3.0 was used to carry out the model tests (using ANOVA). The finding of this study would be beneficial in enriching the data bases for the pressure vessel industry, chemical industry, petroleum and hydrogen storage industry where surfacing having a very vital role.

Bhardwaj et al. [7] performed MIG welding on mild steel to achieve the maximum bead width by controlling the welding parameters like nozzle to plate distance (NPD), open circuit voltage (OCV), welding speed, wire feed rate were. For this study, response surface methodology (RSM) with central composite design (CCRD) with the help of Design Expert software is used. After ANOVA analysis, they found that bead width increases with the increase in NPD, OCV and wire feed rate. However, it decreases with increase in welding speed. Maximum bead width was 5.3 $\mathrm{mm}$ at NPD of $18 \mathrm{~mm}$, OCV of $21 \mathrm{~V}$, welding speed of 30 $\mathrm{cm} / \mathrm{min}$ and wire feed rate $9 \mathrm{~m} / \mathrm{min}$ as shown in Figure 3. Patil et al. [8] studied the influence of welding parameters like welding current, welding voltage, welding speed on ultimate tensile strength (UTS) of AISI 1030 mild steel material. A plan of experiments based on Taguchi technique has been used. An Orthogonal array, signal to noise (S/N) ratio and analysis of variance (ANOVA) are employed to study the welding characteristics of material and optimize the welding parameters. The result computed is in form of contribution from each parameter, through which optimal parameters are identified for maximum tensile strength. They observed that welding current and welding speed are major parameters which influence on the tensile strength of welded joint.

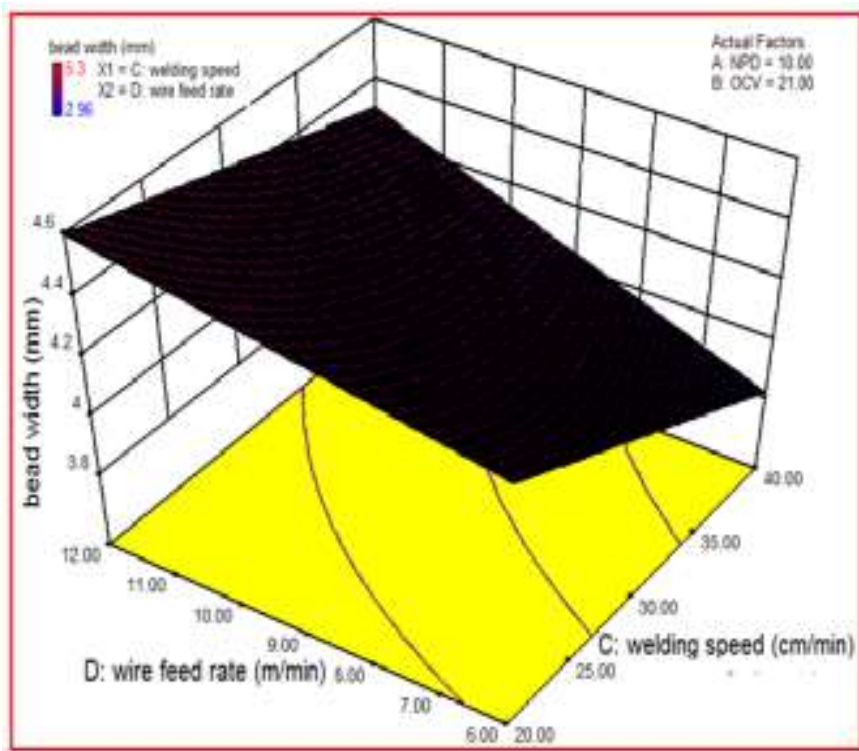

Figure 3. Surface of bead width v/s wire feed rate $\&$ welding speed [7].

Hooda et al. [9] made an attempt to develop a response surface model to predict tensile strength of MIG welded AISI 1040 medium carbon steel joints. The process parameters such as welding voltage, current, wire speed and gas flow rate were studied. The experiments were conducted based on a four-factor, three level and face centered composite design matrix. The empirical relationship can be used to predict the yield strength of material. Response surface methodology (RSM) was applied to optimizing the MIG welding process parameters to attain the maximum yield strength of the joint.

Kumar et al. [10] carried out experiments on 1018 mild steel plates using gas metal arc welding (GMAW) process. $\mathrm{L}_{9}$ orthogonal array of Taguchi`s experimental design was used for optimization of welding current, voltage and gas flow rate on welded joints; class of statistics called signal to noise $(\mathrm{S} / \mathrm{N})$ ratios has been defined to measure the effect of noise factors on performance characteristics. They found the higher tensile strength, which leads to a stronger weld so, larger the better quality characteristic was taken. In Taguchi method signal to noise ratios is used to determine the optimum level of each factor as shown in Table 1.

TABLE I. Analysis for tensile strength and S/N ratio [10].

\begin{tabular}{|c|c|c|c|c|c|}
\hline Run & $\begin{array}{c}\text { Current } \\
\text { (Amp) }\end{array}$ & $\begin{array}{c}\text { Voltage } \\
\text { (Volt) }\end{array}$ & $\begin{array}{c}\text { GFR } \\
\text { (lpm) }\end{array}$ & $\begin{array}{c}\text { Tensile Strength } \\
\text { (MPa) }\end{array}$ & S/N Ratio \\
\hline 1 & 200 & 36 & 15 & 348.3 & 50.8391 \\
\hline 2 & 200 & 38 & 17 & 369.9 & 51.3617 \\
\hline 3 & 200 & 40 & 19 & 386.9 & 51.7520 \\
\hline 4 & 220 & 36 & 17 & 371.9 & 51.4085 \\
\hline 5 & 220 & 38 & 19 & 376.7 & 51.5199 \\
\hline 6 & 220 & 40 & 15 & 394.0 & 51.9099 \\
\hline 7 & 240 & 36 & 19 & 360.2 & 51.1309 \\
\hline 8 & 240 & 38 & 15 & 367.8 & 51.3122 \\
\hline 9 & 240 & 40 & 17 & 392.4 & 51.8746 \\
\hline
\end{tabular}


Sapakal et al. [11] depict the influence of welding parameters like welding current, welding voltage, welding speed on penetration depth of MS C20 material through MIG welding. Taguchi technique has been used to acquire the data. An Orthogonal array, signal to noise $(\mathrm{S} / \mathrm{N})$ ratio and analysis of variance (ANOVA) are employed to investigate the welding characteristics of MS C20 material. The predicated values with the experimental values confirm the effectiveness in the analysis of penetration by them.

Patel et al. [12] used full factorial method for Design of Experiment in optimization work. By use of the experimental data optimal process parameter combination was achieved by grey relational analysis (GRA) optimization technique. AISI 1020 or C20 material was used for welding. They used ANOVA analysis and concluded that the welding current is most significant parameter for MIG welding. Welding current is reported to have effect on hardness. Increase in welding current, the value of hardness is reported as increased. They found through the GRA optimization technique that optimal parameter combination is meeting at experiment 6 and its parameter value is 100 Amp welding current, $1.2 \mathrm{~mm}$ wire diameter and $3 \mathrm{~m} / \mathrm{min}$ wire feed rate for MIG welding as shown in Figure 4.

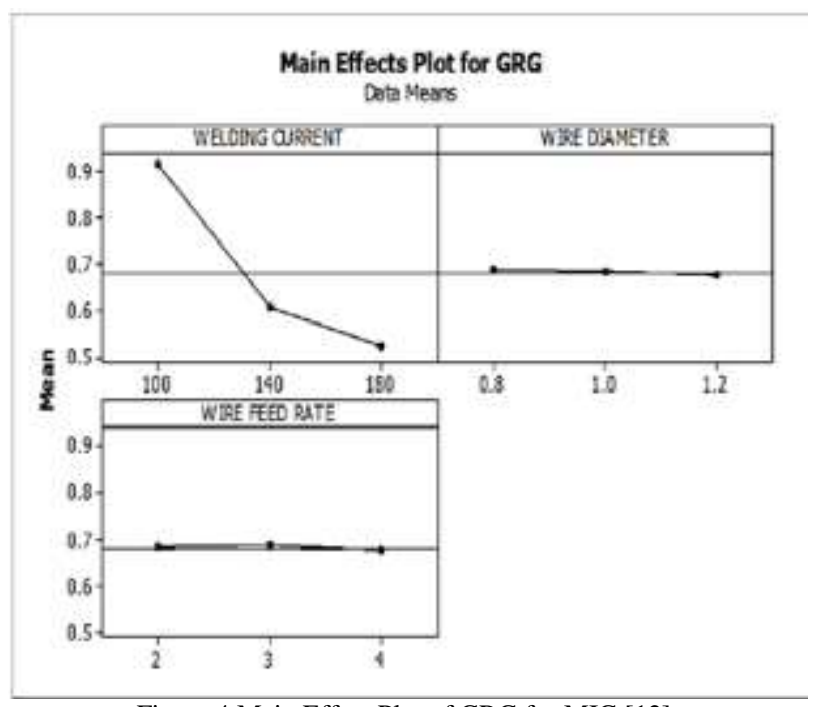

Figure 4 Main Effect Plot of GRG for MIG [12].

Ibrahim et al. [13] performed experiments in the effects of different parameters on welding penetration, micro structural and hardness measurement was measured on mild steel $6 \mathrm{~mm}$ thickness of the base metal by using the robotic gas metal arc welding. As a result, it is found that increasing the parameter value of welding current increased the value of depth of penetration. Figure 5 shows the effect of welding current on penetration with welding speed as constant as 20 $\mathrm{cm} / \mathrm{min}$ and the value of penetration was found increased by increasing the value of welding current 90,150 and $210 \mathrm{~A}$. They found the highest penetration as $2.98 \mathrm{~mm}$ at $22 \mathrm{~V}$ and $210 \mathrm{~A}$. At welding speed $40 \mathrm{~cm} / \mathrm{min}$ the value of penetration was found to be increased by increasing the value of welding current. They observed the highest penetration as $2.79 \mathrm{~mm}$ at $26 \mathrm{~V}$ and $210 \mathrm{~A}$. They concluded that depth of penetration increased by increasing the value of welding current. It is also found that the grain boundaries of microstructures changes from bigger size to smallest size when the variable welding parameters changed.

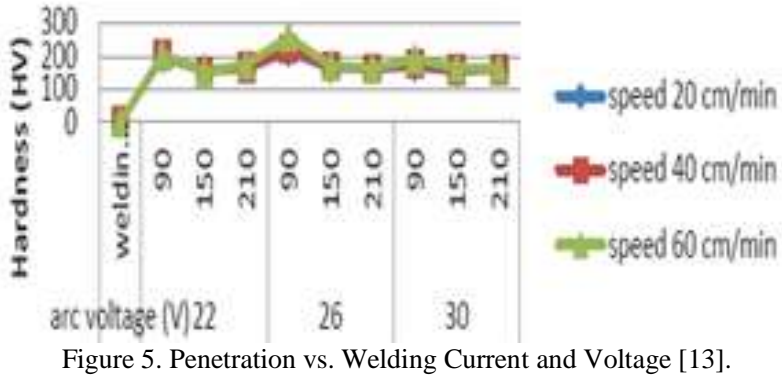

Bataineh et al. [14] was identified and optimized the main factors that have significant effect on weld joint strength through factorial design experiments. Welding experiments were carried out with an ER1100 filler wire with $1.2 \mathrm{~mm}$ in diameter was used as a consumable electrode. The shielding gas used as pure Argon for 1070 aluminum alloy. The factors that were studied are arc voltage, filler feed rate, gas flow rate, specimen edge angle and preheat temperature. Results of factorial design experiments and the analysis of variance (ANOVA) showed that arc voltage and filler feed rate are the only significant factors of the five. Correia et al. [15] explored the possibility of using Genetic Algorithms (GA) as a method to decide near-optimal settings of a GMAW welding process. The problem was to choose the near best values of three control variables (welding voltage, wire feed rate and welding speed) based on four quality responses (deposition efficiency, bead width, depth of penetration and reinforcement), inside a previous delimited experimental region. Shoeb et al. [16] found the welding parameters such as welding speed, voltage and gas flow rate were varied on HSLA steel [IS 304] and the effects of these parameters on weld bead geometry such as penetration, width and height have been studied. Mathematical equations have been developed using factorial technique. And the results of various effects are studied.

Haragopal et al. [17] presented a method to design process parameters that optimize the mechanical properties of weld specimen for aluminum alloy (Al-65032), used for construction of aerospace wings. The process parameters considered for the study were gas pressure, current, groove angle and pre-heat temperature. Process parameters were assigned for each experiment. The experiments were conducted using the orthogonal array. Analysis of variance (ANOVA) has predicted significant parameters identified through S/N analysis. Meshram et al. [18] has performed a research on stainless steel (AISI410) for optimization of process parameters of gas metal arc welding to improve the quality of weld bead geometry. They studied a grey based Taguchi method, however, welding process parameters were arc voltage, wire feed rate, welding speed, nozzle to plate distance and gas flow. The quality characteristics consider were penetration, reinforcement and bead width. Analysis of variance has performed to find the effect of individual process parameter on quality parameters by them. Taguchi $\mathrm{L}_{25}$ array was adopted to conduct the experiments. Kocher et al. [19] studied for the material IS 2062 E250 Mild Steel and studied input parameter as welding speed variable while arc voltage $(\mathrm{V})$, welding current $(\mathrm{A})$, wire feed rate $(\mathrm{W})$, distance between the nozzle and the plates were fixed and the response was the effect of weld speed on penetration and 
reinforcement. This study was carried out by them to determine the effects of weld speed on the weld profile and dilution analysis of the MIG butt welds of IS2062 E250 a mild steel plates at constant wire speed rate and constant arc voltage and welding current. Pasupathy et al. [20] studied for the material AA1050 low carbon steel and take input parameter as welding current, welding speed, distance of electrode from work piece and the response was signal to noise $(\mathrm{S} \backslash \mathrm{N})$, ANOVA (analysis of variance) for strength. The experiment value was observed from optimal welding parameters, the strength and $\mathrm{S} / \mathrm{N}$ ratio. Pal et al. [21] studied optimization of quality characteristics parameters in a pulsed metal inert gas welding process using grey based Taguchi method. The optimization methods used in this study are appropriate for modeling, control and optimizing the different welding process. Huang et al. [22] presented the effect of each welding parameter on the weld bead geometry, and then sets out to determine the optimal process parameters using the Taguchi method to determine the parameters.

\section{Concluding Remarks}

There are many researchers carried out study and analysis by DoE as optimization techniques. Welding current, arc voltage, welding speed, type of shielding gas, gas flow rate, wire feed rate, diameter of electrode etc. are the important control parameters of MIG welding process. They affect the weld quality in terms of mechanical properties and weld bead geometry. The value of depth of penetration increased by increasing the value of welding current and the grain boundaries of the microstructure are varied when the welding parameters are changed. Taguchi Technique shall be used to conduct the experiments. The Taguchi method has become an influential tool for improving output during research and development, so that better quality products can be produced quickly and at minimum cost.

\section{References}

[1] ASM Handbook Volume 6: "Welding, Brazing, and Soldering" Editor: D.L. Olson, T.A. Siewert, S. Liu, G.R. Edwards, ASM International 1993.J. Clerk Maxwell, A Treatise on Electricity and Magnetism, 3rd ed., vol. 2. Oxford: Clarendon, 1892, pp.68-73.

[2] H.B. Cary, "Modern Welding Technology", Prentice Hall 5th ed. 2001.

[3] D.C. Montgomery, "Design and analysis of experiments" 8th ed. Wiley Publisher, 2001.

[4] C. Howard, "Modern welding technology", Prentice Hall, 1979.

[5] L. P. Connur, "Welding Handbook vol 1 and 2, American Welding Society, 1989 and 1990.

[6] T.K. Jha, B. Bhardwaj, K. Bhagat, V. Sharma, "A review paper prediction and optimization of weld bead geometry in gas metal arc welding process using d-optimal methodology", International Journal of Science, Engineering And Technology, vol. 2 Issue 7, 2014, pp. $1455-1459$

[7] V.B. Bhardwaj, K. Bhagat, M. Choubisa, "Prediction and optimization of weld bead geometry in gas metal arc welding process using d-optimal methodology", International Journal of Science, Engineering And Technology, vol. 2 Issue 7, 2014.

[8] S.R. Patil, C.A. Waghmare, "Optimization of MIG welding parameters for improving strength of welded joints", International Journal of Advanced Engineering and Studies, 2013, pp.14-16.

[9] A. Hooda, A. Dhingra and S. Sharma, "Optimization of welding process parameters to predict maximum yield strength in AISI 1040",
International Journal of Mechanical Engineering and Robotics Research, India, pp. 204-212.

[10] D. Kumar and S. Jindal,"Optimization of process parameters of gas metal ARC Welding by Taguchi's experimental design method, International Journal of Surface Engineering \& Materials Technology, Vol. 4, No. 1, 2014, ISSN: 2249-7250.

[11] S.V. Sapakal and M.T. Telsang "Weld ability And Process Parameter Optimization Of Dissimilar Pipe Joints Using GTAW," International Journal Of Engineering Research And Applications (Ijera), vol. 2, Issue 3, pp. 2525-2530.

[12] C.N. Patel and S. Chaudhary, "Parametric Optimization Of Weld Strength Of Metal Inert Gas Welding And Tungsten Inert Gas Welding By Using Analysis of Variance And Grey Relational Analysis" Modern Engineering And Emerging Technology, Vol. 1, Issue: 3, April-2013.

[13] I.A. Ibrahim Syarul, A. Mohamat, A. Aamir, "The Effect of Gas Metal Arc Welding (GMAW) Processes on Different Welding Parameters", International Symposium on Robotics and Intelligent Sensors 2012 (Iris 2012), 2012.07.342.

[14] O. Bataineh, A. Al-Shoubaki, O. Barqawi "Optimizing Process Conditions In Mig Welding of Aluminum Alloys Through Factorial Design Experiments" Latest Trends In Environmental And Manufacturing Engineering, ISBN: 978-1-61804-135-7.

[15] D.S. Correia, C.V. Gonçalves, Sebastião S. C. Junior and V.A. Ferraresi , "GMAW Welding Optimization Using Genetic Algorithms", J. of the Braz. Soc. of Mech. Sci. \& Eng., Vol. XXVI, No. 1, January-March 2004

[16] M. Shoeb, M. Parvez, P. Kumari,"Effect of MIG Welding Input Process Parameters on Weld Bead Geometry On Hsla Steel", ISSN : 0975-5462, Vol. 5 No.01 January 2013.

[17] G. Haragopal, P V R Ravindra Reddy, G Chandra Mohan Reddy And J V Subrahmanyam, "Parametric Design For MIG Welding of Al65032 Alloy Using Taguchi Technique", Journal of Scientific And Industrial Research, vol. 70, October 2011, pp.844-858.

[18] S.R. Meshram and N.S.Pohokar "Optimization of Process Parameters of Gas Metal Arc Welding to Improve Quality of Weld Bead Geometry". 2321-0613, Volume-1, Issue 9, 2013.

[19] G. Kocher "Experimental Analysis In MIG Welding With IS 2062/250 A Steel With Various Effects" International Journal of Advanced Engineering Technology, April-June, 2012, 158-162.

[20] J. Pasupathy, V. Ravisankar "Parametric Optimization of TIG Welding Parameters Using Taguchi Method for Dissimilar Joint", International Journal of Scientific \& Engineering Research, November-2013.

[21] S. Pal, S.K. Malviya, S.K. Pal and A. K. Samantaray, "Optimization of Quality Characteristics Parameters In A Pulsed Metal Inert Gas Welding Process Using Grey-Based Taguchi Method," Int J Adv Manuf Technol (2009)44:1250-1260, DOI 10.1007/S00170-0091931-0.

[22] Her-Yueh Huang, "Grey Based Taguchi Method For Optimization of Bead Geometry in Submerged arc Bead-on-Plate Welding", International Journal Of Advance Manufacturing Technology (2008) 39:1136-1143.

About Author (s):

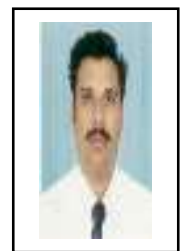

[Dr. B.F. Jogi has completed BE, M Tech (Mechanical Engineering with Gold Medal), PhD from IIT Bombay, Mumbai. He has 18 years of teaching and research experience. He has presented papers in Canada, Korea, Germany, India, etc. He has also delivered many experts lecturers] 